$\underline{\text { Avicenna Journal of Nursing and Midwifery Care - ISSN 2676-5748 }}$

\title{
Investigating the Demographic Characteristics, Clinical Signs, Radiological and Laboratory Findings in Pregnant Women with COVID-19: A Cross-Sectional Study in Southern Iran
}

\author{
Parisa Sabetsarvestani ${ }^{1}$, Soheila Rahnavard ${ }^{2}$, Mahmood Hatami ${ }^{3}$, Mostafa Bijani ${ }^{4 *}$, Leila Nikrooz ${ }^{4}$
}

1. Instructor, Department of Medical-Surgical Nursing, Fasa University of Medical Sciences Fasa, Iran

2. Student Research Committee, Fasa University of Medical Sciences, Fasa, Iran

3. Instructor, Department of Medical-Surgical Nursing, Fasa University of Medical Sciences Fasa, Iran

4. Associate Professor, Department of Medical-Surgical Nursing, Fasa University of Medical Sciences Fasa, Iran

\begin{tabular}{lll}
\hline \multicolumn{1}{c}{ Article Info } & & ABSTRACT \\
\cline { 1 - 1 } Received: $2020 / 09 / 09 ;$ & & $\begin{array}{l}\text { Introduction: Pregnant women are one of the vulnerable groups against COVID-19. } \\
\text { effective treatment goals; in this regard, the present study tries to review demographic } \\
\text { Accepted: } 2020 / 11 / 23 ;\end{array}$ \\
Published Online: $2021 / 09 / 21$ & $\begin{array}{l}\text { chacteristics, clinical signs, radiological and laboratory findings in pregnant women with } \\
\text { COVID-19 in southern Iran. }\end{array}$
\end{tabular}

10.30699/ajnmc.29.3.256

Original Article

Use your device to scan and read the article online

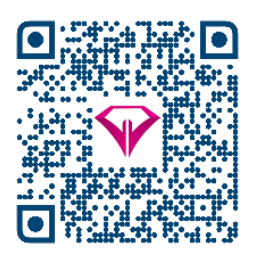

Methods: This descriptive cross-sectional study was conducted on 30 pregnant women with COVID-19 who were selected from teaching hospitals in Fasa, Jahrom, and Shiraz in Fars province. Sampling was done through the convenience method from March to July 2020. A researcher-made checklist was applied to gather the required data which were analyzed using SPSS 22 software and descriptive statistics.

Results: The mean age of patients was $28.30 \pm 9.96$ years. Of patients, $60 \%$ were in the first trimester of pregnancy. The average length of stay in a hospital was $8.47 \pm 4.37$ days. Fever $(46 / 66$ $\%$ ) was the most common clinical finding, increased C-reactive protein (CRP) levels (50\%) was the most common laboratory finding, and Ground Glossy Opacity (GGO) (56/66 \%) was the most common radiological finding in both lungs. Of pregnant women, $80 \%$ with COVID-19 had an underlying disease. The most common underlying diseases were $36.66 \%$ for asthma and $20 \%$ for diabetes. Of normal deliveries, $53.33 \%$ and $3.33 \%$ of neonatal and maternal deaths were reported.

Conclusion: The most common time for COVID-19 in pregnant women was reported in the first trimester of pregnancy with clinical signs of fever and a history of asthma and diabetes. Therefore, the findings of this study highlight the importance of paying attention to pregnant women as one of the most at-risk groups in the COVID-19 pandemic. Health policy makers can use the findings of this study and the reported outcomes to develop appropriate health protocols for health care of pregnant women in the COVID-19 pandemic.

Keywords: COVID-19, Coronavirus, Demography, Pregnant women

Corresponding Information:

Mostafa Bijani, Associate Professor, Department of Medical-Surgical Nursing, Fasa University of Medical Sciences Fasa, Iran. Email: bizhani_mostafa@yahoo.com

Copyright $\odot$ 2021, This is an original open-access article distributed under the terms of the Creative Commons Attribution-noncommercial 4.0 International License which permits copy and redistribution of the material just in noncommercial usages with proper citation.

How to Cite This Article:

Sabetsarvestani P, Rahnavard S, Hatami M, Bijani M, Nikrooz L. Investigating the Demographic Characteristics, Clinical Signs, Radiological and Laboratory Findings in Pregnant Women with COVID19: A Cross-Sectional Study in Southern Iran. Avicenna J Nurs Midwifery Care. 2021; 29 (3):256-263 
بررسى ويزگَىهاى جمعيتشناختى، علأمم بالينى، يافتههاى راديولوزى و آزمايشَاهى در زنان حاملةُ مبتلا به كرونا ويروس ( كوويد- 19 ) : مطالعة توصيفى مقطعى در جنوب ينائ ايران

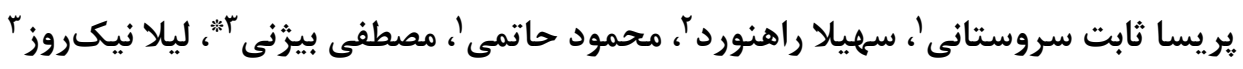

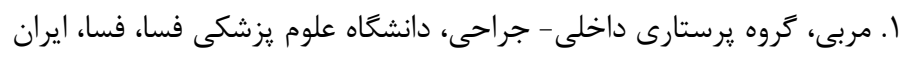

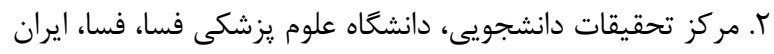

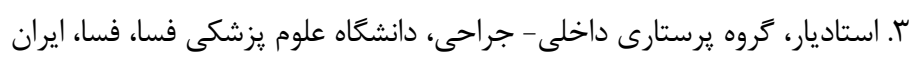

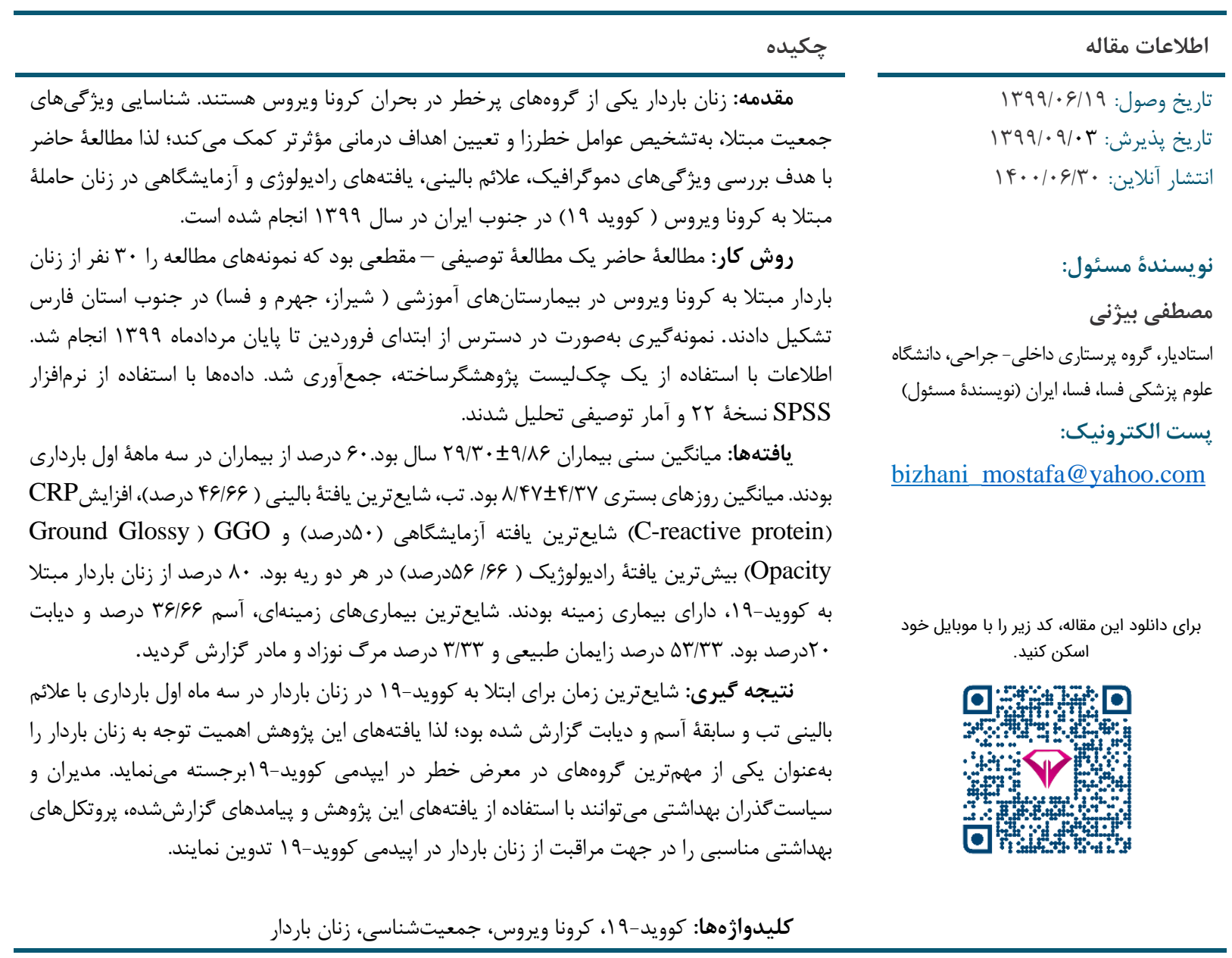

مقدمه

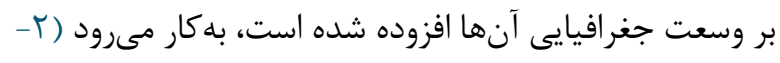

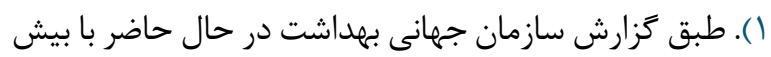

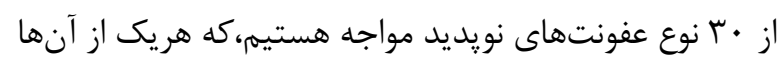
با توجه به نوع، وسعت و شدت تهديدى كه ايجاد كرده است،

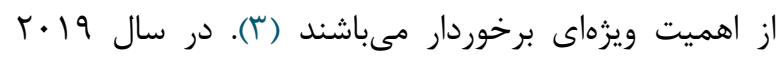

وازٔه نويديدى ' را در مورد بيمارىهاى عفونى كه براى اولينبار در سطح جهان، منطقه يا جمعيت جديدى عارض مىشوند و يا عفونتهاى بيمارىزايى كه قبلا وجود داشته؛ ولى يلى

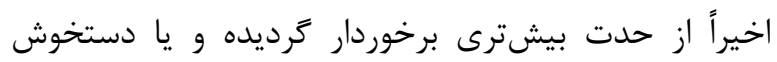

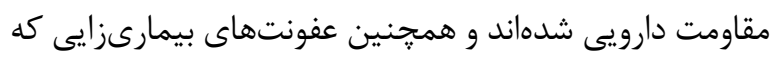

\section{1 . Emerging}


مطالعه حاضر يك مطالعه توصيفى - مقطعى است كه نمونههاى آن را كليئ زنان باردار مبتلا به كوويد-9 اتشكيل دادند. معيار ورود به مطالعه، شامل بسترى شدن بلهعلت كوويد-9 او نداشتن اختلالات ذهنى و روحئ ورود به معيار خروج از مطالعه، ناقص بودن اطلاعات بيماران بودند. نمونهگيرى بهصورت دردسترس انجام شد. بدين منظوركليئ زنان باردار

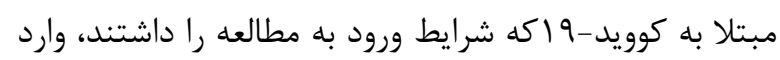

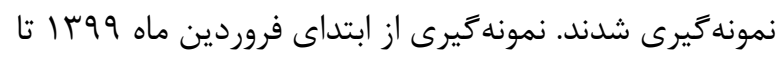

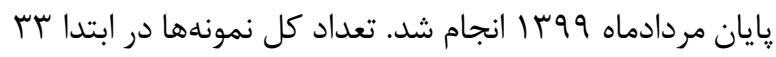
نفر بود. اطلاعات يرونده سه نفر از بيماران ناقص بود؛ لذا در برد

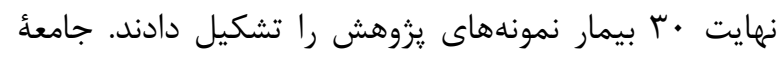
هدف در :روهش، شامل بيمارستانهاى آموزشى ( شيراز، جهرم و فسا) در جنوب استان فارس بودند. بدين منظور

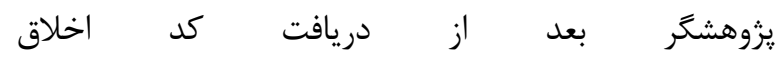
(IR.FUMS.REC.1399.093) با استفاده از يك جك تهليست

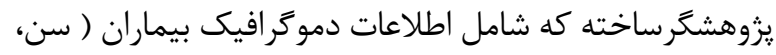
ميزان تحصيلات، شغل، تعداد زايمان، ماه باردارى )، اطلاعات

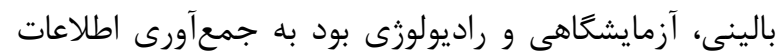

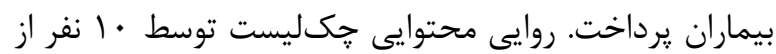

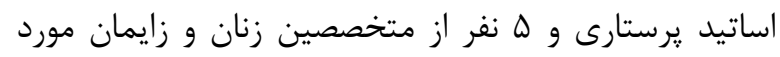

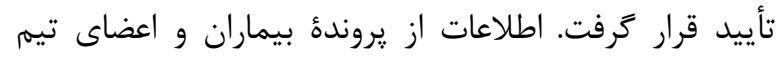
درمان، شامل يرستاران و يزشكان معالج جمعآورى گرديد. SPSS Inc., ) دادهها با استفاده از نرمافزار SPSS نسخئ (Chicago, Ill., USA

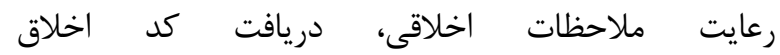

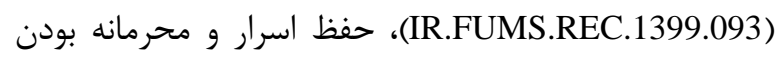
اطلاعات بيماران و نيز در اختيار قرار دادن اطلاعات يزوهش به مراكز تحتمطالعه بهعنوان ملاحظات اخلاقى رعايت گرديد.

\section{بافته ها}

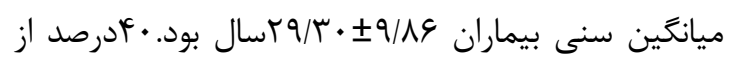

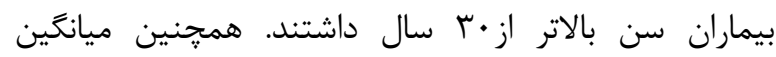

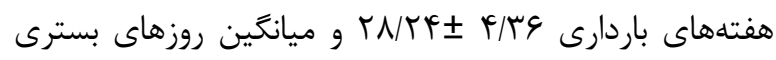

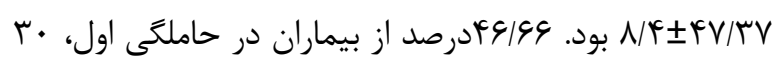

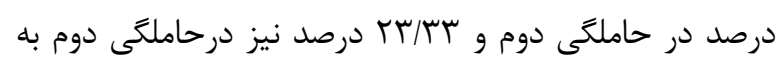

بيمارى نويديد كرونا ويروس ( كوويد- 9 (1) از جين شروع شده و سيس در تمام كشورهاى جهان بهطور جشمَّى

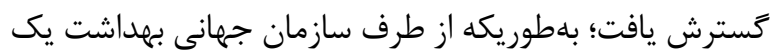

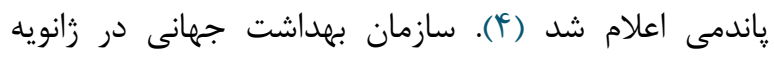

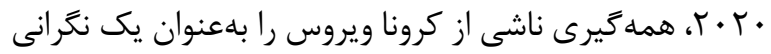
و اضطراب بهداشت عمومى بينالمللى معرفى نمود (ه). طبق لـ

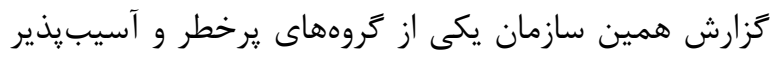

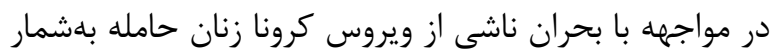
مىآيند كه استرس و فشارهاى روانى سنگينى را تجربه مى كنند (Y-Y). زنان حامله بهعلت تغييرات فيزيولوزيكى در

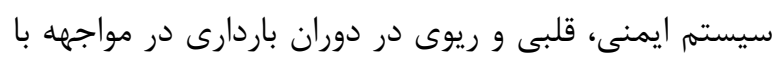
عفونتها، بلهصوص عفونتهاى تنفسى ويروسى آسيبيذير

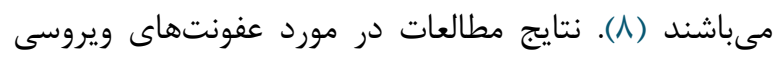

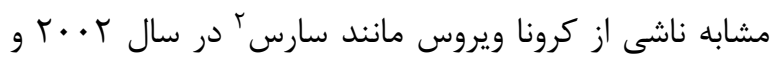

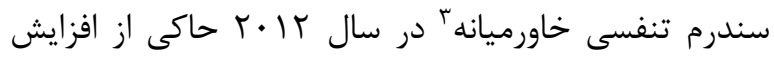

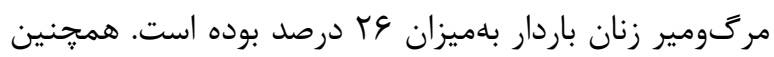

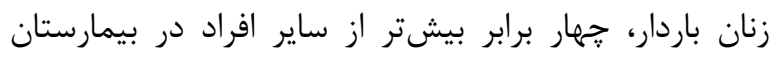
بسترى بودهاند ( • (1-9).

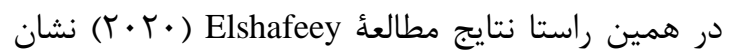
داد از 9 زن باردار كه تست كرونا مثبت داشتند، نوزاد دو نفر از بيماران، دجار عوارض ديسترس جنينى شده بودند و عارضء ياركى زودرس يردههاى جنينى در دو نفر از زنان باردار مبتلا

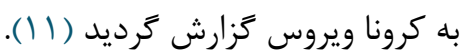
در حال حاضر مطالعات اندكى در زمينهُ تأثيركرونا ويروس كروس بر حاملكى انجام شده است. با توجه به اينكه مطالعات در اين زمينه مىتواند نقش مهمى در برنامهريزى و سياست گذارى نظام سلامت در تشخيص، ييش زيرى و درمان اين بيمارى در

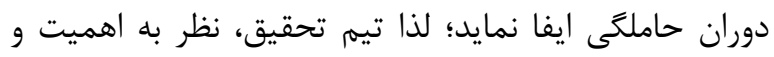

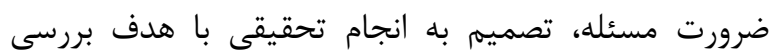

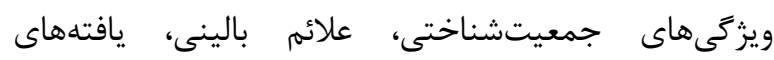
راديولوزى و آزمايشَاهى در زنان حاملهُ بسترى با كرونا ويروس

$$
\text { ( كوويد -9 (1) در جنوب ايران نمود. }
$$

$$
\text { روش كار }
$$

1 . Coronavirus (COVID-19)

2 . Severe acute respiratory syndrome (SARS)

4. Middle East respiratory syndrome (MERS) 
شايعترين يافتُٔ غيرطبيعى (C-reactive protein) CRP

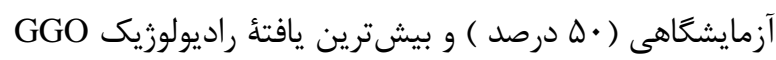
(Ground Glossy Opacity)

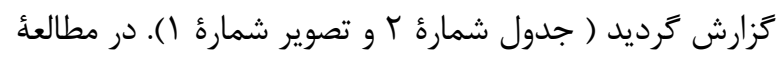
حاضر س س/سه درصد از زنان باردار مبتلا به كوويد-9 1 زايمان طبيعى داشتند و س// درصد مرى نوزاد و مادر زَزارش گرديد. ساير ريامدها در جدول شماره ب بيان شده است.
بعد مبتلا به كوويد-9 اشده بودند. •9 درصد از بيماران در سه

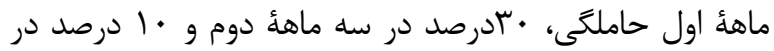
سه ماهؤ سوم باردارى بودند. •ع درصد از بيماران خانهدار

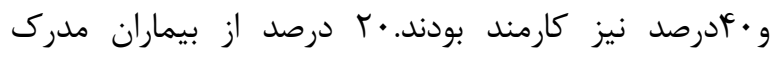

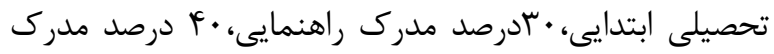
دييلم و • ادرصد مدرك تحصيلى ليسانس داشتند ( جدول

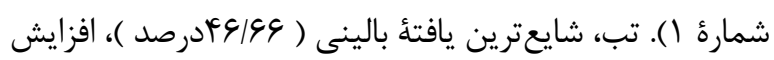

جدول شمارهُ ا. ويزَّى هاى جمعيتشناسى نمونههاى مورد يثزوهش

\begin{tabular}{|c|c|c|c|}
\hline درصد & تعداد & & \\
\hline 1. & r & كمتر از r & \multirow{4}{*}{ سن } \\
\hline$r$. & 4 & TtTH & \\
\hline r. & 9 & $r \varepsilon_{-} r$. & \\
\hline f. & ir & بالاتر از • r & \\
\hline$r \cdot$ & 9 & ابتدايى & \multirow{4}{*}{ تحصيلات } \\
\hline$r$. & 9 & راهنمايى & \\
\hline f. & IT & دييلم & \\
\hline 1. & r & ل ليسانس & \\
\hline 4. & 11 & خانه دار & \multirow{2}{*}{ وضعيت اشتغال } \\
\hline f. & ir & 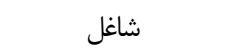 & \\
\hline r. & 4 & ديابت & \multirow{5}{*}{ بيمارى زمينه اى } \\
\hline r9|99 & 11 & آسم & \\
\hline אוא/Tו & r & كم كارى تيروئيد & \\
\hline 1. & r & فشارخون & \\
\hline$r \cdot$ & 9 & بدون بيمارى زمينه اى & \\
\hline 4. & 11 & سه ماهد اول & \multirow{3}{*}{ سن باردارى } \\
\hline$r$. & 9 & سه ماهه دوم & \\
\hline 1. & r & سه ماهل سوم & \\
\hline Fq199 & $1 f$ & باردارى اول & \multirow{3}{*}{ نوبت باردارى } \\
\hline$r$. & 9 & باردارى دوم & \\
\hline אسז/Wr & v & باردارى دوم به بعد & \\
\hline
\end{tabular}

جدول شماره r. علائم بالينى، آزمايشعاهى و راديولوزى در زنان حاملهُ مبتلا به كوويد-19

\begin{tabular}{|c|c|c|c|}
\hline درصد & تعداد & يافته ها & متغير \\
\hline FE| & If & تب & \\
\hline 19199 & $\Delta$ & سرفه & \\
\hline 9199 & r & تنغى نفس & \\
\hline 9199 & r & 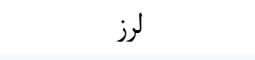 & علاثم بالينى \\
\hline 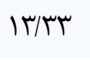 & f & احساس خستخى مفرط & \\
\hline
\end{tabular}




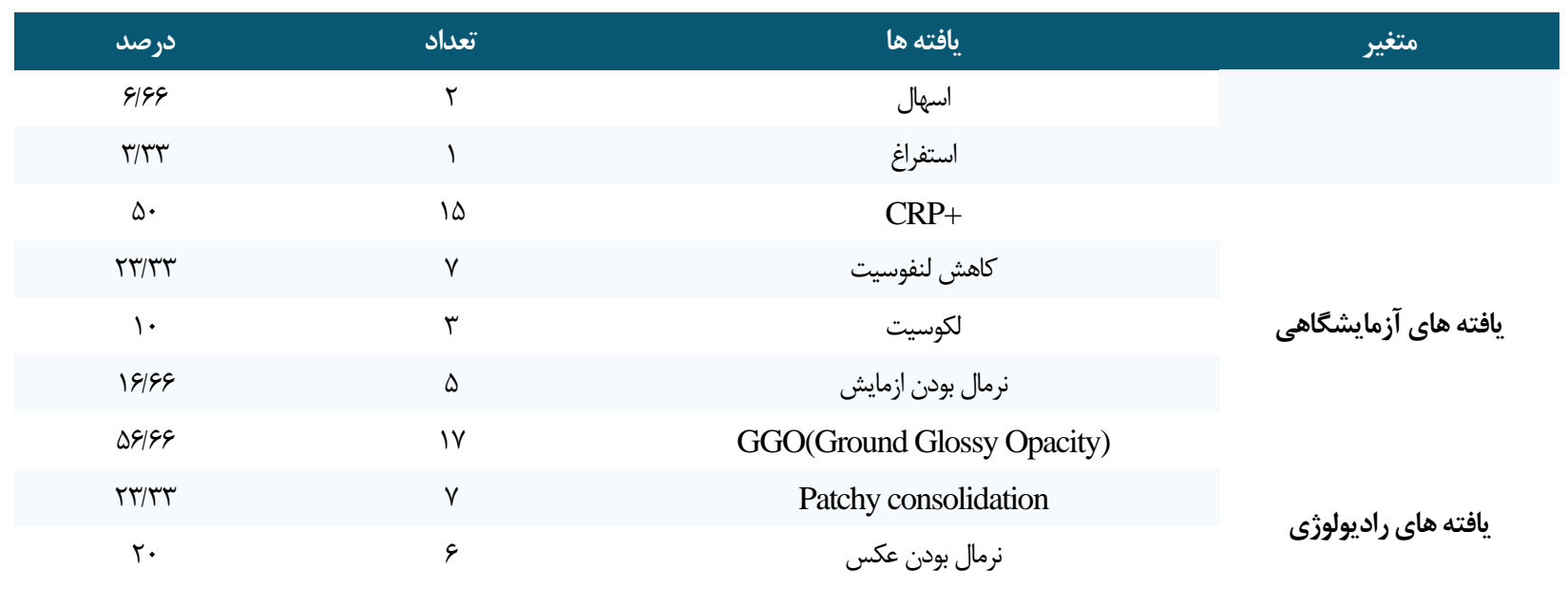

جدول شماره س. يِيامدهاى باردارى در زنان باردار مبتلا به كوويد- 19 در نمونههاى مورد يزوهش

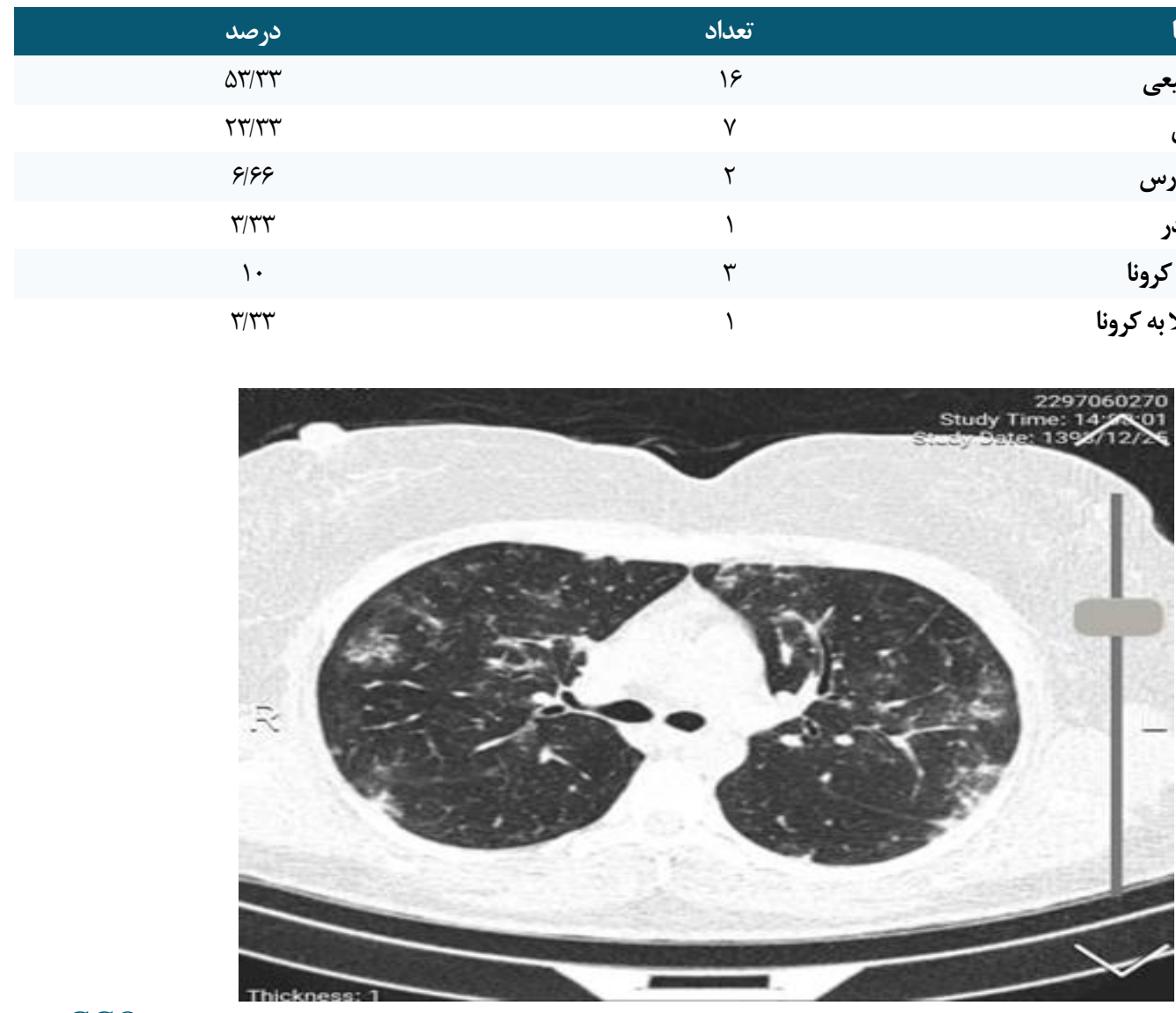

تصوير شماره ا. سى تى اسكن ريه يك خانم حامله كه با علائم تب و سرفه و تشخيص كوويد -19 بسترى شده است. در تصوير GGO سى

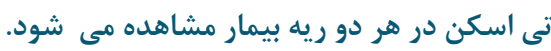

بحث

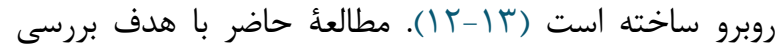

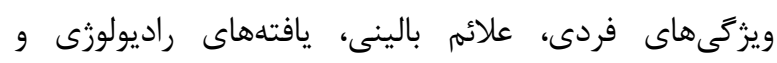

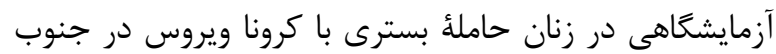
ايران انجام شده است. در مطالعهُ انجامشده، بيشترين علائم
وضعيت فعلى كرونا ويروس در سراسر جهان شديد و نخران كننده است و تعداد زنان باردار مبتلا به اين ويروس درون

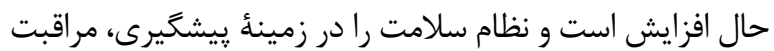
و درمان زنان باردار در دوران ياندمى كرونا ويروس را با جالش 
مزمن تنفسى در زنان حامله منجر به مستعد نمودن آنها براى ابتلا به كرونا ويروس، تشديد عوارض جانبى بيمارى و نيز

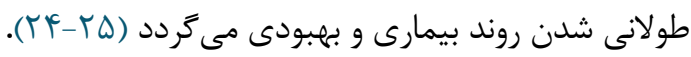

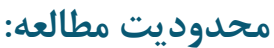

از جمله محدوديتهاى مطالعهُ حاضر، مىتوان به كم بودن تعداد نمونهها اشاره نمود كه مىتواند ناشى از انجام مطالعات

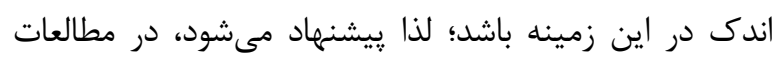

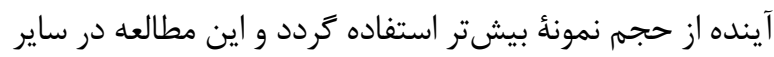

$$
\text { مناطق كشور انجام كيرد. }
$$

$$
\text { نتيجه كَيرى }
$$

شايعترين زمان براى ابتلا به كوويد-19 در زنان باردار در

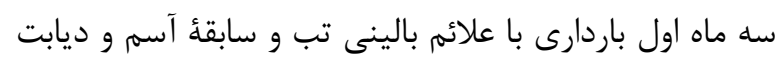

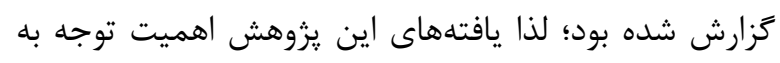

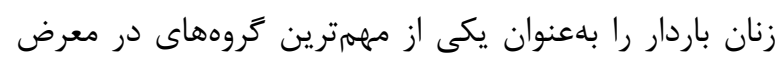

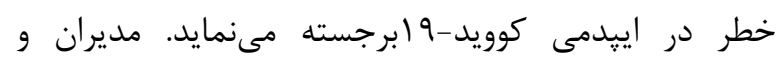

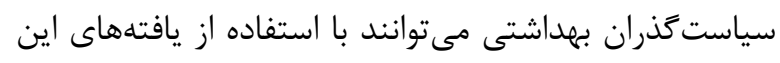

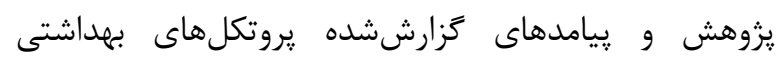

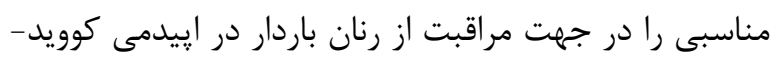
9 ا تدوين نمايند.

\section{سياسگزارى}

اين مطالعه از معاونت تحقيقات دانشگاه علوم يزشكى فسا

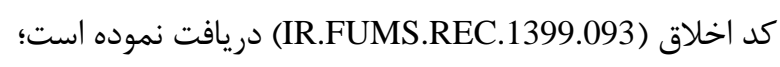

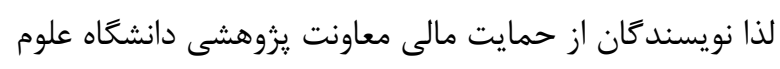
يزشكى فسا و حمايت مالى واحد توسعه و تحقيقات بالينى مالى مانى بيمارستان ولى عصر (عج) فسا قدردانى مى نمايند.

$$
\text { تعارض در منافع }
$$

نويسند

$$
\text { منابع مالى مالى }
$$

منابع مالى اين يزوهش توسط معاونت يزوهشى دانشكاه علوم

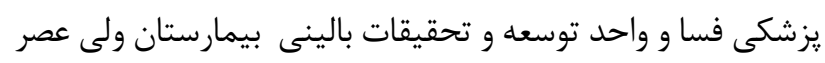
(عج) فسا تأمين شده است.
بالينى، تب گزارش گَرديد. نتايج مطالعه

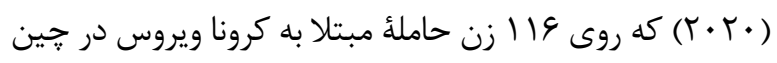

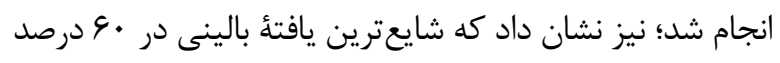

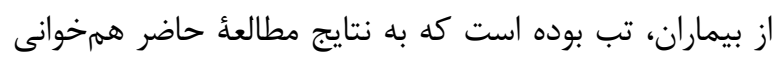

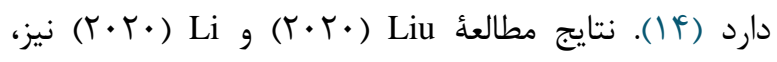

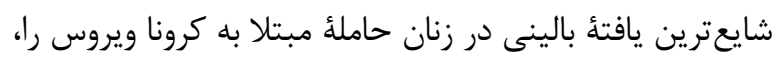

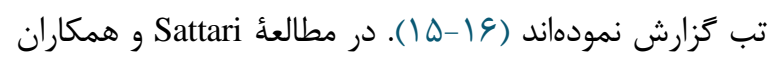

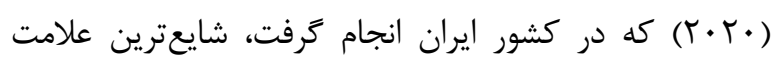

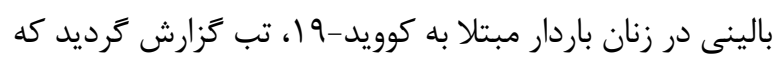

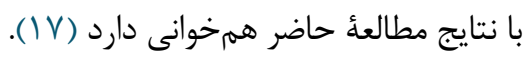

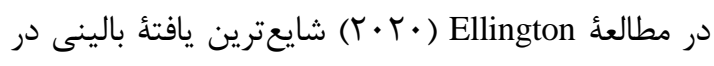

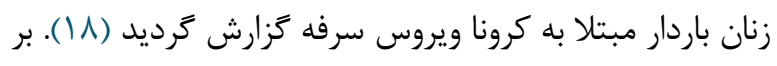

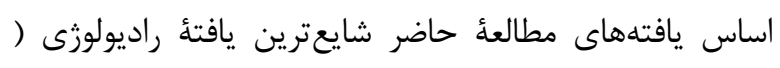
سى تىاسكن ) در هو درصد از بيماران (Grand Glossy GGO) Opacity

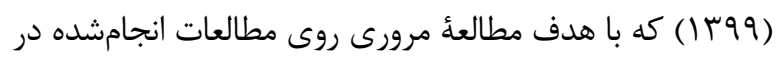

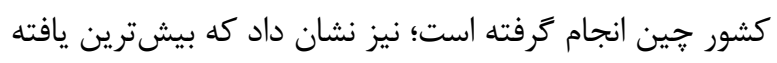

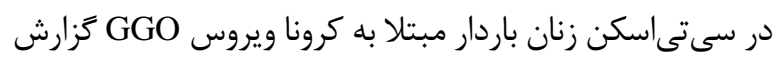

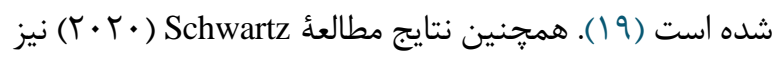

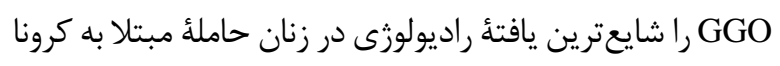

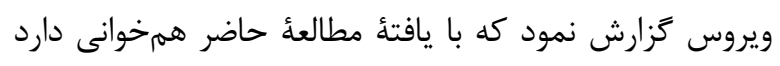

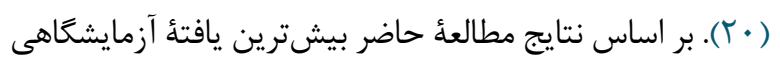

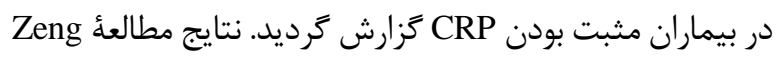

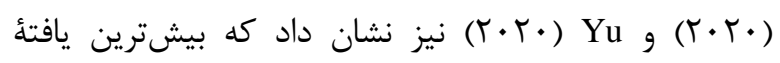

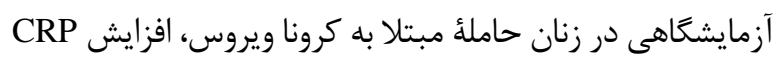

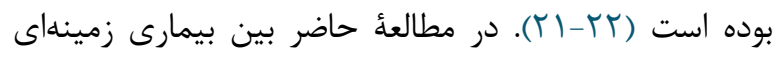

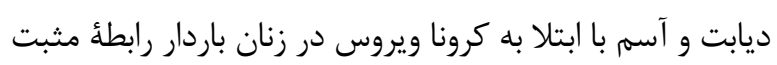
آمارى مشاهده كرديد.

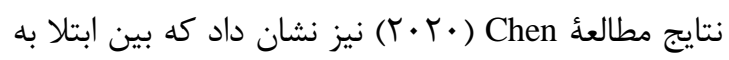

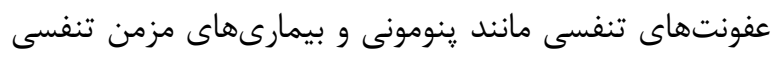

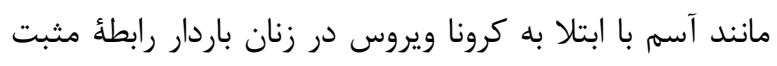

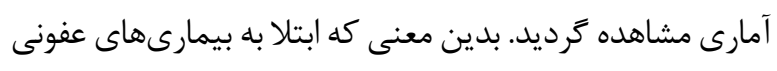

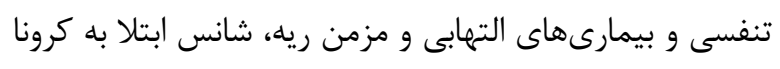

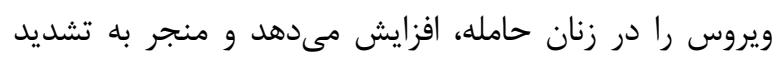

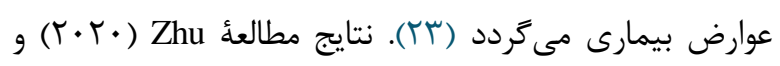

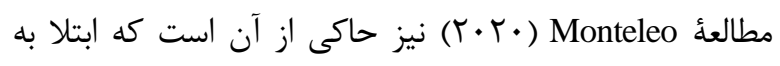

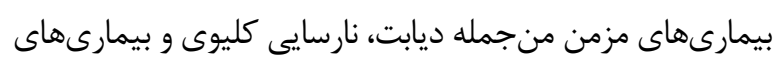




\section{References}

1. Huang C, Wang Y, Li X, Ren L, Zhao J, Hu Y, et al. Clinical features of patients infected with 2019 novel coronavirus in Wuhan, China. Lancet. 2020;395(10223):497-506. [DOI:10.1016/S01406736(20)30183-5]

2. Wang D, Hu B, Hu C, Zhu F, Liu X, Zhang J, et al. Clinical characteristics of 138 hospitalized patients with 2019 novel coronavirus-infected pneumonia in Wuhan, China. Jama. 2020;323(11):1061-9. [DOI:10.1001/jama.2020.1585] [PMID] [PMCID]

3. World Health Organization. Clinical management of severe acute respiratory infection (SARI) when COVID-19 disease is suspected: interim guidance, 13 March 2020. World Health Organ;2020. Available at: https://apps.who.int [DOI:10.15557/PiMR.2020.0003]

4. Greenberg N, Docherty M, Gnanapragasam S, Wessely S. Managing mental health challenges faced by healthcare workers during COVID-19 pandemic. BMJ. 2020;368:1-4 [DOI:10.1136/bmj.m1211] [PMID]

5. Wang J, Zhou M, Liu, F. Reasons for health care workers becoming infected with novel coronavirus disease 2019 (COVID-19) in China. J Hosp Infect. 2020;105:100-1.

[DOI:10.1016/j.jhin.2020.03.002] [PMID] [PMCID]

6. Zhu N, Zhang D, Wang W, Li X, Yang B, Song J, et al. A novel coronavirus from patients with pneumonia in China, 2019. N Engl J Med. 2020;382(8):727-33 [DOI:10.1056/NE]Moa2001017] [PMID] [PMCID]

7. Baud D, Qi X, Nielsen-Saines K, Musso D, Pomar L, Favre G. Real estimates of mortality following COVID19 infection. Lancet Infect Dis. 2020;20(7):773. [DOI: 10.1016/S1473-3099(20)30195-X]

8. Chen H, Guo J, Wang C, Luo F, Yu X, Zhang W, et al. Clinical characteristics and intrauterine vertical transmission potential of COVID-19 infection in nine pregnant women: a retrospective review of medical records. The lancet. 2020 Mar 7;395(10226):809-15. [DOI: 10.1016/S0140-6736(20)30360-3]

9. Farnoosh G, Alishiri G, Zijoud SH, Dorostkar R, Farahani AJ. Understanding the Severe acute respiratory syndrome coronavirus 2 (SARS-CoV-2) and coronavirus disease (COVID-19) based on available evidence - a narrative review. J Mil Med. 2020; 22 (1):1-11

10. Park MH, Kim HR, Choi DH, Sung JH, Kim JH. Emergency cesarean section in an epidemic of the middle east respiratory syndrome: a case report. Korean J Anesthesiol. 2016;69(3):287 [DOI:10.4097/kjae.2016.69.3.287] [PMID] [PMCID]
11. Elshafeey F, Magdi R, Hindi N, Elshebiny M, Farrag $\mathrm{N}$, Mahdy S, et al. A systematic scoping review of COVID-19 during pregnancy and childbirth. Int $\mathbf{J}$ Gynecol Obstet. 2020. [DOI: 10.1002/ijgo.13182] [PMID]

12. Poon LC, Yang H, Lee JC, Copel JA, Leung TY, Zhang Y, et al. ISUOG Interim Guidance on 2019 novel coronavirus infection during pregnancy and puerperium: information for healthcare professionals. Ultrasound Obstet Gynecol. 2020; 55(5):700-8. [DOI:10.1002/uog.22013] [PMID] [PMCID]

13. Qiao J. What are the risks of COVID-19 infection in pregnant women? Lancet. 2020; 395(10226):760-2. [DOI: 10.1016/S0140-6736(20)30365-2]

14. Yang H, Wang C, Poon LC. Novel coronavirus infection and pregnancy. Ultrasound Obstet Gynecol. 2020; 55(4):435-7 [DOI:10.1002/uog.22006] [PMID] [PMCID]

15. Liu D, Li L, Wu X, Zheng D, Wang J, Yang L, et al. Pregnancy and Perinatal Outcomes of Women With Coronavirus Disease (COVID-19) Pneumonia: A Preliminary Analysis. Am J Roentgenol. 2020:1-6. [DOI:10.2139/ssrn.3548758]

16. Li Q, Guan X, Wu P, Wang X, Zhou L, Tong Y, et al. Early transmission dynamics in Wuhan, China, of novel coronavirus-infected pneumonia. $\mathrm{N}$ Engl $\mathrm{J}$ Med. 2020;382(13):1199-207

[DOI:10.1056/NE]Moa2001316] [PMID] [PMCID]

17. Sattari M, Bashirian S, Masoumi SZ, Shayan A, Jenabi E, Ghelichkhani S, et al. Evaluating Clinical Course and risk factors of Infection and demographic characteristics of pregnant women with COVID-19 in Hamadan Province, West of Iran. J Res Health Sci. 2020; 20(3): 1-5 [DOI:10.34172/jrhs.2020.22] [PMID] [PMCID]

18. Ellington S, Strid P, Tong VT, Woodworth K, Galang RR, Zambrano LD, et al. Characteristics of women of reproductive age with laboratory-confirmed SARSCoV-2 infection by pregnancy status - United States, January 22-June 7, 2020. Morb Mortal Wkly Rep. 2020;69(25):770-5

[DOI:10.15585/mmwr.mm6925a1] [PMID] [PMCID]

19. Nikpour M, Behmanesh F, Darzipoor M, Haddad Zavareh MS. Pregnancy outcomes and clinical manifestations of Covid-19 in Pregnant Women: a narrative review. J Mil Med. 2020;22(2):177-83

20. Schwartz DA. An Analysis of 38 Pregnant Women with COVID-19, Their newborn infants, and maternal-fetal transmission of SARS-CoV-2: maternal coronavirus infections and pregnancy outcomes. Arch Pathol Lab Med. 2020;144(7):799-805 [DOI:10.5858/arpa.2020-0901-SA] [PMID] 
21. Zeng L, Xia S, Yuan W, Yan K, Xiao F, Shao J, et al. Neonatal early-onset infection with SARSCoV-2 in 33 neonates born to mothers with COVID-19 in Wuhan, China. JAMA Pediatr 2020;174(7):722-5 [DOI: 10.1001/jamapediatrics.2020.0878] [PMID] [PMCID]

22. Yu N, Li W, Kang Q, Xiong Z, Wang S, Lin X, et al. Clinical features and obstetric and outcomes of pregnant patients with COVID-19 in Wuhan, China: a retrospective, single-centre,descriptive study. Lancet Infect Dis. 2020;20:559-64 [DOI:10.1016/S14733099(20)30176-6]
23. Zhu H, Wang L, Fang C, Peng S, Zhang L, Chang G, Xia S, Zhou W. Clinical analysis of 10 neonates born to mothers with 2019-nCoV pneumonia. Transl Pediatr. 2020;9:51-60. doi: 10.21037/tp.2020.02.06. [DOI:10.21037/tp.2020.02.06] [PMID] [PMCID]

24. Monteleone PA, Nakano M, Lazar V, Gomes AP, de Martin H, Bonetti TC. A review of initial data on pregnancy during the COVID-19 outbreak: implications for assisted reproductive treatments. JBRA Assist Reprod. 2020; 24(2): 219-25. [DOI: 10.5935/1518-0557.20200030] [PMID] [PMCID] 